\title{
YOUTH
}

HOMELESSNESS STRATEGY 


\section{YOUTH HOMELESSNESS STRATEGY}


(C) Government of Ireland 2001

ISBN 0-7076-9263-6

BAILE ÁTHA CLIATH:

ARNA FHOILSIÚ AG OIFIG AN TSOLÁTHAIR.

Le ceannach díreach ón

OIFIG DHÍOLTA FOILSEACHÁN RIALTAIS, TEACH SUN ALLIANCE,

SRÁID THEACH LAIGHEAN, BAILE ÁTHA CLIATH 2,

nó tríd an bpost ó

FOILSEACHÁIN RIALTAIS, AN RANNÓG POST-TRÁCHTA,

4-5 BÓTHAR FHEARCHAIR, BAILE ÁTHA CLIATH 2,

(Teil: 01-647 6834/35/36/37; Fax: 01-475 2760)

nó trí aon díoltóir leabhar.

DUBLIN:

PUBLISHED BY THE STATIONERY OFFICE.

To be purchased directly from the

GOVERNMENT PUBLICATIONS SALE OFFICE, SUN ALLIANCE HOUSE, MOLESWORTH STREET, DUBLIN 2,

or by mail order from

GOVERNMENT PUBLICATIONS, POSTAL TRADE SECTION,

4-5 HARCOURT ROAD, DUBLIN 2 ,

(Tel: 01-647 6834/35/36/37; Fax: 01-475 2760)

or through any bookseller.

Price: IR£4.00

$€ 5.08$

Gr. 30-01 10/01 5,000 Brunswick Press Ltd. (5177) 
The goal of this Strategy is: "to reduce and if possible eliminate youth homelessness through preventative strategies and where a child becomes homeless to ensure that he/she benefits from a comprehensive range of services aimed at re-integrating him/her into his/her community as quickly as possible."

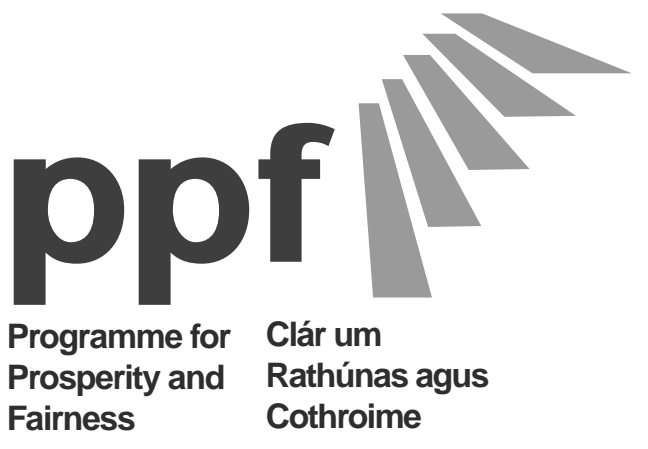




\section{Table of Contents:}

Foreword by the Minister for Children

\section{Chapter 1}

1.1

1.2

1.3

1.4

\section{Chapter 2}

2.1

2.2

2.3

2.4

2.5

2.6

2.7

2.8

2.9

\section{Chapter 3}

3.1

3.2

3.3

3.4

3.5

3.6

\section{Introduction}

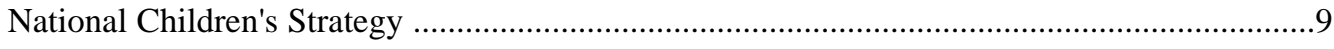

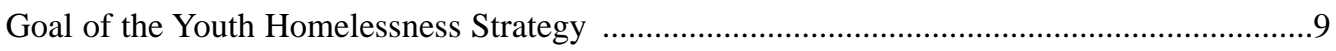

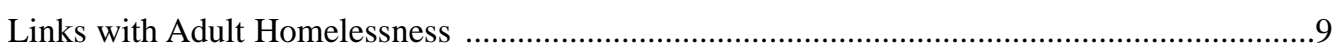

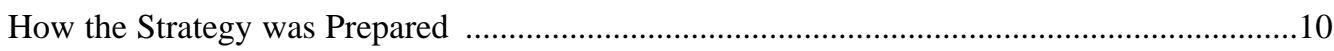

\section{Context of Youth Homelessness}

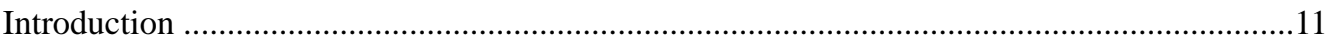

Definition of Youth Homelessness ....................................................................................11

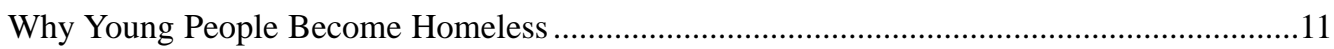

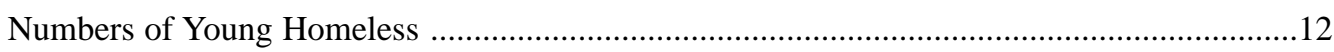

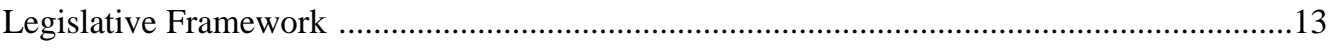

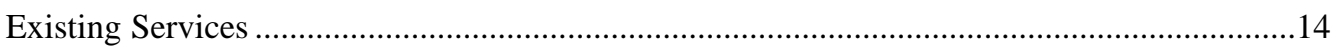

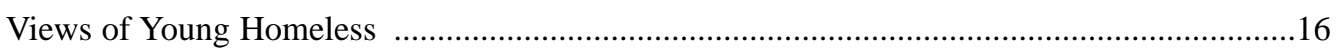

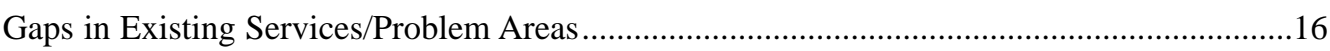

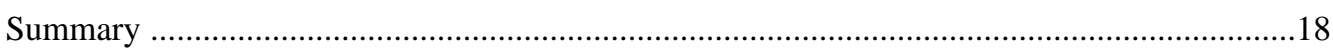

\section{Objectives of the Strategy}

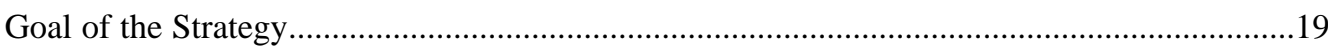

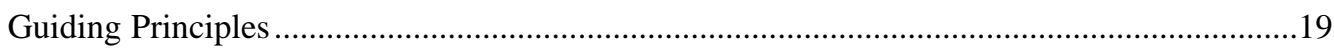

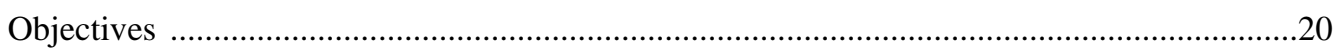

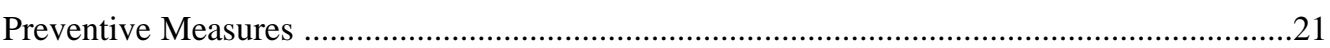

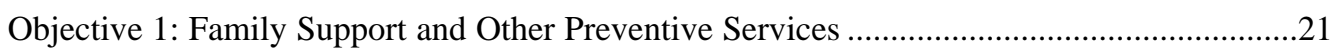

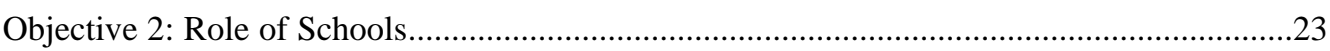

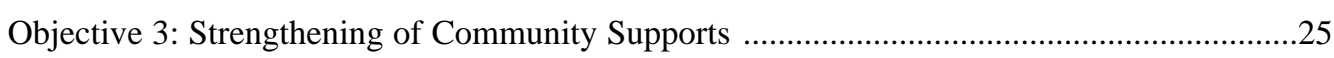

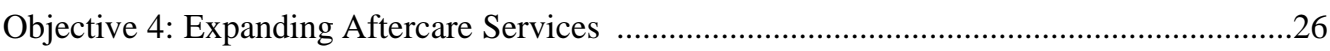

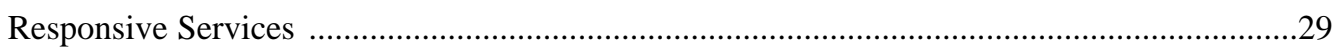

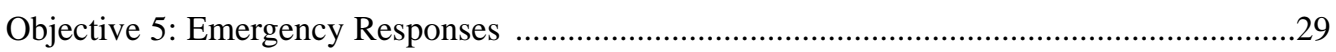

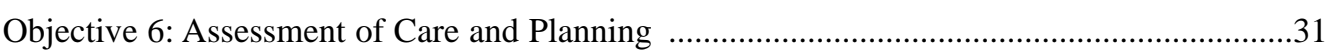

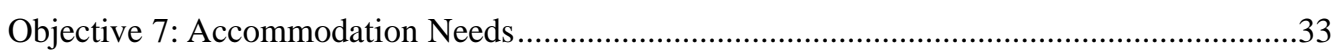

Objective 8: Health, Educational and Recreational Needs .........................................................

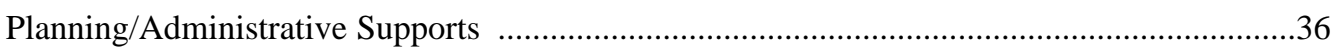

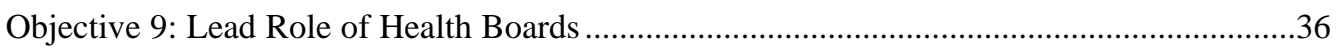

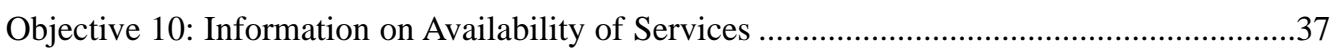

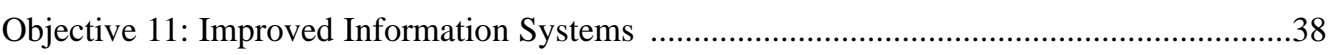

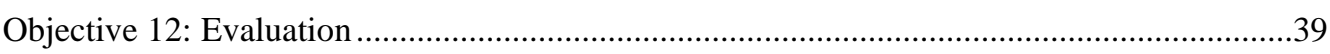

\section{Chapter 4 Implementation of the Strategy}

Health Board Two Year Strategic Plan to Address Youth Homelessness ...................................41

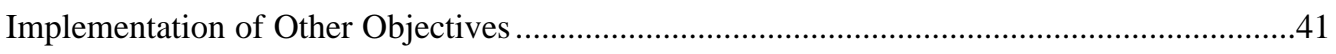

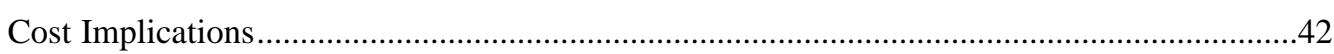




\section{Appendices}

Appendix 1: Objective H National Children's Strategy .......................................................43

Appendix 2: Documents and Publications consulted in the preparation of the Strategy ..........45 


\section{FOREWORD BY THE MINISTER FOR CHILDREN}

Homelessness among children and young people is one of the most significant forms of social exclusion.

Substantial progress has been made in recent years in putting health board, voluntary and other services in place for young homeless people. Our aim must be to eliminate youth homelessness.

This Strategy aims to build on this work and to ensure a more co-ordinated and planned approach to tackling youth homelessness. Particular emphasis is placed on prevention and on the importance of supporting schools, communities, the young people themselves and their families in this context. Where a young person becomes homeless the Strategy stresses the need for a prompt child focused service which will address the individual needs of the young person.

The Youth Homelessness Strategy complements the Government's Strategy on adult and family homelessness 'Homelessness - An Integrated Strategy' which was launched last year.

Ni ceart go mbeadh páiste gan dídean. Leis an Straitéis seo beimid in ann ár fadhbanna a sheachaint agus a réiteach.

I am confident that the Youth Homelessness Strategy will make a real difference in tackling this important social issue.

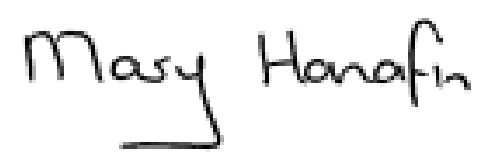
Mary Hanafin T.D.
Minister For Children 


\section{CHAPTER 1}

\section{Introduction}

\subsection{National Children's Strategy}

The National Children's Strategy was published in November 2000. The vision underlying The National Children's Strategy, is: "An Ireland where children are respected as young citizens with a valued contribution to make and a voice of their own; where all children are cherished and supported by family and a wider society; where they enjoy a fulfilling childhood" (The National Children's Strategy Page 4).

The National Children's Strategy identified the development of a National Strategy on Youth Homelessness as a priority in addressing youth homelessness. One of the objectives of The National Children's Strategy is that:

"Children will have access to accommodation appropriate to their needs".

The full text of the Strategy in regard to this objective is at Appendix 1.

The National Children's Strategy is a major social policy development in that it addresses the needs of all children and provides a coherent policy for a broad range of issues affecting children's lives. The Strategy provides for new structures which are intended to bring a better focus and impact to government activity in relation to children, in particular through improved coordination.

The 'whole child' perspective which informs The National Children's Strategy also informs this national Youth Homelessness Strategy.

\subsection{Goal of the Youth Homelessness Strategy}

The goal of this Strategy is: "to reduce and if possible eliminate youth homelessness through preventative strategies and where a child becomes homeless to ensure that he/she benefits from a comprehensive range of services aimed at reintegrating him/her into his/her community as quickly as possible."

It sets out the objectives and the steps required to achieve this. It places particular emphasis on preventing youth homelessness and on the importance of supporting schools, communities and young people themselves and their families.

Where youth homelessness occurs the Strategy stresses the need for a prompt responsive child focused service. It recognises the importance of co-ordinated inter-agency working in tackling this complex multi-dimensional issue.

\subsection{Links with Adult Homelessness}

This Strategy complements the Government's National Anti-Poverty Strategy and the strategy on adult and family homelessness - "Homelessness - An Integrated Strategy" 2000 published by the Department of the Environment and Local Government and the forthcoming "Preventative Strategies - Homelessness" to be published by the same Department.

It is hoped that this Strategy will be a significant step in realising the vision underlying The National Children's Strategy for some of our most marginalised children and in so doing help to make our society a more inclusive one. 


\subsection{How the Strategy was Prepared}

The Strategy draws on a number of reports on youth homelessness and child welfare issues including an initial consultant's report on youth homelessness prepared for the Department of Health and Children in March 2000. In particular the analysis and recommendations of the Report of the Forum on Youth Homelessness in the Eastern Region and the Report of the Review Group on Crisis Intervention Services for Children has fed into the preparation of the strategy. The results of the wide ranging public consultation process undertaken in preparing The National Children's Strategy, which included the views of young homeless people, were also taken into account. In addition the Social Services Inspectorate, the Eastern Regional Health Authority and the Health Boards were consulted on the strategy. The strategy also benefited from the views of members of the Youth Homeless Providers Forum in the Eastern Region. 


\section{CHAPTER 2}

\section{Context of Youth Homelessness}

\subsection{Introduction}

Homelessness is one of the most visible signs of social deprivation. The current Government is determined to address the issue of homelessness, and the Government Programme, An Action Programme for the Millennium, contains commitments in regard to both child and adult homelessness. In relation to children, a key priority is a:

"Review of all investigative, therapeutic and prevention services to protect children, including:

- services to address child begging, child homelessness and child prostitution."

While this Strategy focuses primarily on youth or child homelessness, it is important to note the links between youth and adult homelessness. A 1992 Simon Community survey found that there was a link between people who were homeless as teenagers and later experienced adult homelessness. The Survey showed $20 \%$ of homeless persons had stayed in a shelter as a teenager and $25 \%$ had slept rough as a teenager.

\subsection{Definition of Youth Homelessness}

Youth homelessness is different from adult homelessness in a number of ways. The key difference is that the vast majority of children under the age of 18 have a place of residence from which to operate; this may be their home, or an alternative form of accommodation supplied by a health board or a voluntary agency. In essence, when a young person becomes homeless, it is because they can no longer operate from this base. The term "out of home" rather than homeless is sometimes used when referring to children who are homeless, as this takes cognisance of the fact that there is a place of residence available which has become for whatever reason, a place where the young person feels that she or he can no longer live. Homelessness is more than lacking material items, it is also a cause of mental distress characterised by insecurity and low self esteem.

The Forum on Youth Homelessness adopted the following definition of homelessness consistent with that of the Homeless Initiative:

"Those who are sleeping on the streets or in other places not intended for night-time accommodation or not providing safe protection from the elements or those whose usual night-time residence is a public or private shelter, emergency lodging, $B \& B$ or such, providing protection from the elements but lacking the other characteristics of a home and/or intended only for a short stay."

The Forum included within this meaning "young people who look for accommodation from the Eastern Health Board Out of Hours Service" and "those in insecure accommodation with relatives or friends regarded as inappropriate, that is to say where the young person is placed at risk or where he or she is not in a position to remain".

This is also the definition of homelessness for the purposes of this strategy.

\subsection{Why Young People Become Homeless}

Becoming homeless is a process as opposed to a single event and there are many reasons why homelessness can occur.

Table 2.1 provides data on the reasons why young people become homeless. This data which relates to cases of children who presented as homeless to health boards during the year 2000 was supplied by health boards for the Department of Health and Children's Child Care Interim Minimum Data Set (see Section 2.4 below). The single most frequent reason given is family problems, followed by emotional/behavioural problems, and physical abuse. The range of services provided by health boards in these cases is outlined at 2.6. 
Table 2.1 Number of Children who presented to the Health Boards in 2000 as Homeless by reason for Homelessness.

\begin{tabular}{|l|c|c|c|}
\hline Primary Reason & Number of Males & Number of Females & Total \\
\hline Physical Abuse of Child & 36 & 27 & 63 \\
\hline Sexual Abuse of Child & 8 & 7 & 15 \\
\hline Emotional Abuse of Child & 2 & 3 & 14 \\
\hline Neglect of Child & 5 & 9 & 36 \\
\hline Parents unable to cope/ & 22 & 14 & 30 \\
Parental Illness & 13 & 17 & 110 \\
\hline Parents Abusing Drugs/Alcohol & 60 & 50 & 54 \\
\hline Children with Emotional/ & 25 & 29 & 124 \\
Behavioural Problems & 48 & 76 & 16 \\
\hline Child Abandoned/Rejected & 7 & 9 & 8 \\
\hline Family Problems & 0 & 8 & 45 \\
\hline Domestic Violence & 20 & 25 & 68 \\
\hline Pregnancy & 43 & 25 & $\mathbf{5 8 8}$ \\
\hline Child or Young Person & $\mathbf{2 8 9}$ & $\mathbf{2 9 9}$ & \\
\hline Abusing Alcohol or Drugs & & & \\
\hline Other & & & \\
\hline TOTAL & & & \\
\hline
\end{tabular}

\section{$2.4 \quad$ Numbers of Young Homeless}

There are difficulties in accurately measuring the number of homeless young people in Ireland. These include the challenge posed by the nature of homelessness particularly the phenomenon of "hidden homelessness" where young people do not come to the attention of the health board community care team or to other state services in the ordinary course (see Section 2.8 below).

The Out of Hours Service operated by the former Eastern Health Board recorded between 59 and 78 individuals dealt with on a monthly basis between January and June 1999. Counted In - The Report of the 1999 Assessment of Homelessness in Dublin, Kildare and Wicklow which was a snap-shot survey carried out on behalf of the Homeless Initiative, recorded a figure of 160 young people aged 18 or under deemed "homeless" in the week of 25 March, 1999.

The Department of Health and Children is addressing current information deficits by undertaking a major review of the information requirements of the child care services with a view to establishing a National Child Care Management Information System. In the meantime an Interim Minimum Data Set was devised to provide routine data including national data on youth homelessness. Figures collated by the Department of Health and Children on the basis of information supplied by the health boards for the Interim Minimum Data Set, indicate that in the year 2000, 588 cases of homeless children were dealt with by health boards. This compares with a figure of 774 cases of homeless children which were dealt with by health boards in 1999 . The range of support including residential and assisted independent living accommodation, foster care and return home etc provided by health boards in such cases is outlined at Section 2.6 which follows.

Table 2.2 gives a breakdown by Health Board/Authority area of the number of children who presented as homeless in 2000. 
Table 2.2 Number of Children who Presented as Homeless in 2000 by Health Board/Authority area, and as a \% of National Total.

\begin{tabular}{|l|c|c|}
\hline Health Board & $\begin{array}{c}\text { No of cases of Children who } \\
\text { presented as Homeless in 2000 }\end{array}$ & $\begin{array}{c}\text { Children as \% of National } \\
\text { Total }\end{array}$ \\
\hline ERHA & 268 & 45.58 \\
\hline MHB & 9 & 1.53 \\
\hline MWHB & 60 & 10.2 \\
\hline NEHB & 19 & 3.23 \\
\hline NWHB & 6 & 1.02 \\
\hline SEHB & 110 & 18.71 \\
\hline SHB & 79 & 13.44 \\
\hline WHB & 37 & 6.29 \\
\hline Total & $\mathbf{5 8 8}$ & $\mathbf{1 0 0}$ \\
\hline
\end{tabular}

Table 2.2 indicates that youth homelessness is primarily an urban phenomenon. $45.58 \%$ of all children who presented to the boards as homeless in 2000 were located in the Eastern Regional Health Authority area while 13.44\% were in the Southern Health Board region primarily in Cork city and $10.20 \%$ were in the Mid-Western Health Board area, mainly in Limerick city. Health Boards have indicated that it is important to recognise that youth homelessness also occurs to some extent in rural areas. The range of services provided by health boards in these cases is detailed at 2.6.

Table 2.3 Age and Gender of Children who presented to the Health Boards as Homeless in 2000

\begin{tabular}{|l|c|c|c|}
\hline Age & Number of Males & Number of Females & Total \\
\hline Under 12 Years & 31 & 30 & 61 \\
\hline $12-14$ Years & 71 & 53 & 124 \\
\hline $15-16$ Years & 122 & 103 & 225 \\
\hline $17-18$ Years & 65 & 113 & 178 \\
\hline Total & $\mathbf{2 8 9}$ & $\mathbf{2 9 9}$ & $\mathbf{5 8 8}$ \\
\hline
\end{tabular}

Table 2.3 shows that marginally more females presented. 403 i.e. $69 \%$ of those presenting as homeless were aged between 15 and 18 years.

\subsection{Legislative Framework}

\section{The Child Care Act, 1991}

The Child Care Act, 1991 places a legal obligation on each health board to promote the welfare of children in its area who are not receiving adequate care and attention. The Act also provides at Section 5 that "Where it appears to a health board that a child in its area is homeless, the board shall enquire into the child's circumstances, and if the board is satisfied that there is no accommodation available to him which he can reasonably occupy, then, unless the child is received into the care of the board under the provisions of this Act, the board shall take such steps as are reasonable to make available suitable accommodation for him". 


\subsection{Existing Services}

The Child Care Act, 1991 modernised the law in relation to the protection and welfare of children. Services for homeless children are generally provided as part of the child protection and welfare services of health boards. Since mid 1997 over $£ 90$ million (€114.276 million) additional revenue funding has been invested through the health boards in the development of the child welfare services. Approximately $£ 9$ million (€11.428 million) has been targeted at youth homelessness. £7.6 million (€9.650 million) of this has been targeted at the youth homelessness problem in the eastern region including $£ 6.6$ million (€ 8.380 million) in the past two years) These services vary from health board to health board and to date there have been no national guidelines in regard to youth homelessness.

Table 2.4 Primary Service Provided by the Health Boards to children presenting as Homeless

\begin{tabular}{|l|c|c|c|}
\hline Primary Service & Males & Females & Total \\
\hline Financial assistance & 30 & 21 & 51 \\
\hline $\begin{array}{l}\text { Residential/Hostel } \\
\text { Accommodation }\end{array}$ & 108 & 95 & 203 \\
\hline Counselling & 7 & 14 & 21 \\
\hline Outreach Support & 19 & 20 & 39 \\
\hline Assisted Independent & & 24 & 53 \\
\hline Accommodation & 29 & 17 & 29 \\
\hline Foster Placement & 12 & 76 & 71 \\
\hline Returned Home & 45 & 32 & $\mathbf{5 8 8}$ \\
\hline Other & 39 & $\mathbf{2 9 9}$ & \\
\hline TOTAL & $\mathbf{2 8 9}$ & & \\
\hline
\end{tabular}

Table 2.4 which is taken from the data contained in the Department of Health and Children's Interim Minimum Data Set for the year 2000 shows the primary service responses of the health boards to those presenting as homeless.

Eastern Region; Arising from the Forum Report and extensive discussions between the Eastern Regional Health Authority and the Minister for Health and Children, a comprehensive package of child care service developments was agreed in 2000 to tackle youth homelessness in the eastern region. Some of the key provisions of the package are outlined below.

- A Director of Homelessness was appointed in 2000 and each of the three area health boards have appointed an additional Assistant Chief Executive to allow for the enhanced provision of child care and youth homelessness services.

- Outreach services are being expanded and restructured to ensure vulnerable young children are aware of all the new facilities and can avail of them.

- A provider forum which brings together the key statutory and voluntary service providers in the youth homelessness field has been established.

- Each of the three area boards has carried out a review of existing facilities, and properties have been sourced to provide additional hostel/residential care accommodation.

- Multidisciplinary teams are being provided to target young people at risk and/or out of home.

- GP's are being contracted to provide primary health care services for young people who are out of home. 
To date $£ 6.6$ million (€8.380 million) has been made available to support this package of measures. The measures taken emphasise the importance of early intervention in preventing youth homelessness. They involve increasing the number of youth work teams targeting at risk children, and the number of family centres providing support to vulnerable children and their families, as well as expanding family support services. The measures also include additional emergency accommodation, outreach teams, downstream residential places, and the recruitment of additional staff.

In the Midland Health Board cases of youth homelessness are dealt with on an individual basis. Where possible, every effort is made to return the out of home young person to the family home. In the event of this not being possible foster care, residential care or some other alternative arrangement is provided. An Independent Care Project offers a comprehensive service to young homeless persons in Counties Laois and Offaly. The issue of out of home young people is being addressed in the region, in the context of the Board's Child Care Strategy.

In the Mid-Western Health Board services in the main are residential and are based in Limerick City. Services provided include assessment, advice, counselling and a range of therapy options. The Mid-Western Health Board has also developed an adolescent team comprised of a Team Leader and two Social Workers to offer support and assistance to young people who are at risk of homelessness, or experiencing difficulties as a result of homelessness. The service is a regional service based in Limerick City.

A pilot project on aftercare has been launched by the Mid-Western Health Board. The aim of the project is to ensure that children are helped re-integrate into society and into the family setting upon leaving the care of the State.

In the North Eastern Health Board when young people present as out of home, the Board attempts to place them with a member of their extended family. In the event of this not being possible the Board's outreach social work and project officers arrange a suitable alternative such as supported lodgings or supported rented accommodation. The Board has a befriending scheme in Drogheda to engage vulnerable young people and an outreach service in Dundalk.

In the North Western Health Board once a child has been identified as being out of home or at risk of being out of home a care plan is developed for that child. The initial aim is to integrate the young person to their own home. Failing this the board relies on foster placements or placements within its residential centres. The board has contracted youth support placements and respite places which are accessible to children who are out of home. The board are also developing preventative youth projects in which out of home children can become involved. The North Western Health Board is committed to the provision of aftercare services for children leaving care.

The South Eastern Health Board provides a dedicated service for homeless girls which is based in Waterford. When homeless young people present to the board's social work department they are first assessed and where possible a return home is negotiated. Alternatively foster care, supported lodgings, or residential care is provided as appropriate.

A voluntary agency called Doras has been established with a committee representative of local agencies and services, including the South Eastern Health Board in relation to child prostitution. Doras provides an outreach service to children who are involved in or are on the fringes of prostitution.

Since 1995 the Southern Health Board has operated a Homeless Adolescent Unit. The Unit provides a range of practical and clinical support services to homeless adolescents, including emergency shelter, semi-supported accommodation, longer term independent living options, payment of rent, food, meals, clothing, heating and laundry voucher systems as well as personal allowances associated with independent living. The Southern Health Board has also approved a designated general practitioner for the provision of emergency and generic medical care of young homeless people.

Funding has been allocated to the Southern Health Board to provide a short term hostel for adolescent boys. Discussions are now at an advanced stage with a service provider to use an existing building and a manager has been appointed.

The Western Health Board in conjunction with the Galway Diocesan Youth Services have a residential facility in Galway City to accommodate homeless children in the Board's area. Services provided include counselling and other treatment facilities. The Western Health Board have taken a pro-active approach to address the issue of child begging. This comprises a joint approach between the Board, the local authority and the Gardai, and results in the parents of children found begging being cautioned by the relevant authorities. 


\subsection{Views of Young Homeless}

The National Children's Strategy (Published November 2000) emphasises the importance of children and young people having a voice in matters which affect them. The wide ranging public consultation process which was undertaken in preparing The National Children's Strategy records the views of young homeless people. The Report of the Public Consultation on The National Children's Strategy summarises the views of young people who have been homeless as follows.

"A small number of young people wrote of their experience of being homeless. One of their careworkers drew attention to their efforts to remain positive and hopeful, in spite of their experiences. The young people spoke of how they came to live on the streets and the use of drugs to kill the boredom and loneliness of everyday life, the ritual search for accommodation and hot food at night and their wish for a better life and better chances."

Before preparing their report, members of the Forum on Youth Homelessness in the Eastern Region in preparing its report (published April 2000) met with young people in 1999 who were, or had in the past been out of home. While the young people concerned were from the eastern region, their views, and experiences can usefully inform the national strategy. In addition one of the Forum members had been homeless in the recent past and was able to bring a personal perspective to the Forum's work. The issues raised by these young people were summarised in the Forum Report and are reproduced below. While extensive changes in child care and youth homeless services have been introduced in the eastern region over the past year which are outlined at 2.6 above the views of these young people are relevant and account needs to be taken of them in planning services.

\section{The Chaotic Nature of Being Out of Home}

The young people consulted all found the uncertainty in their lives unsettling. Problems were also experienced by having to leave the hostels early in the morning with no organised activities for the rest of the day. The lack of any form of supervision during this period was commented upon. After being left to their own devices every day the children found the structured regimen of the hostels very constricting.

\section{The Out of Hours Service}

The young people felt that beds available through this service should be allocated for more than three nights at a time. Young people under the age of 18 did not like having to wait until $8.00 \mathrm{pm}$ before being able to report for a bed. The method of accessing the Out of Hours Service through a Garda Station was resented. The young people wanted an alternative method of accessing services.

\section{Staff}

While acknowledging that a lot of the staff they dealt with were kind and caring, a view was expressed by some of the children that some staff were untrained, while others did not have any knowledge of the issues facing young people out of home. Some of the young people had bad experiences with the Gardai and advocated the idea of a community Garda who could deal with homeless children directly and have a better understanding of the situation.

\section{Drugs}

All the young people met with acknowledged the fact that drugs were a feature in their lives. All agreed that services were needed for young drug users. There were divergent views as to whether drug users should be segregated from non-drug users. All young people were of the opinion that young people who were using drugs should be provided with accommodation. Many of those spoken to felt that getting help with drugs problems would be a first step towards breaking the cycle of homelessness.

\subsection{Gaps in Existing Services/Problem Areas}

The Report of the Forum on Youth Homelessness (April 2000) identified a number of gaps and problems in service provision in the Eastern Region in 1999. While significant developments in child care and youth homeless services in the Eastern Region over the past year have begun to address these issues it is worth recounting what the Forum said in this context. The problems and gaps identified by the Forum are now described:

\section{Quantification of the Problem}

The Forum Report stressed the difficulties in attempting to quantify the numbers of youth homeless. Because of the nature of and stigma attached to homelessness, many young people shun contact with the relevant authorities. This gives rise to the problem of hidden homelessness. Some people may not wish to be found, they may be drug users, and some may be involved 
in criminal activities. In addition, some young people can drift in and out of homelessness. This may be due to family situations or other circumstances and it makes it difficult to accurately record numbers. Circumstances can also arise where a young person may be double counted as a result of presenting to two different agencies.

\section{Lack of Co-ordination}

Poor co-ordination between current services both voluntary and statutory was identified as a key issue. This can result in fragmented service delivery where homeless young people have to make contact with more than one agency so that their basic needs can be met.

\section{Lack of information on services available}

There is currently no directory showing the range of services and agencies available to homeless youth. In addition, as each agency attempting to tackle the problem keeps its own operational records, there is no single body responsible for the distribution of information.

\section{Funding}

Services for homeless youth receive funding from a wide range of sources including the Eastern Regional Health Authority, Government Departments, the European Union and general fund raising on behalf of the voluntary agencies. Due to a lack of information it is not possible to quantify exactly how much public expenditure and private funding is targeted towards youth homelessness. This lack of knowledge, combined with the current lack of service evaluation, are areas which have been highlighted as needing solutions.

\section{Need to change focus}

The focus of current services is directed towards young people seeking assistance. More resources need to be directed towards early intervention on behalf of those young people deemed to be in need of care and protection as required by the Child Care Act, 1991.

\section{Location of Services}

Many of the emergency services dedicated to children reporting as homeless are located in the city centre. This serves to draw young people towards the city centre which is not really to be encouraged. Services for homeless youth should be located in different areas to avoid "bunching" of children.

\section{Lack of Suitable Accommodation}

It has been acknowledged that there is a lack of suitable accommodation for homeless children. Research from the National Children's Hospital, Temple Street, indicates that hospitals have on some occasions been used for "social admissions". It is obvious that a hospital is not suitable accommodation for a homeless youth and alternative accommodation should be available for those presenting as homeless.

\section{Staffing}

It has long been realised that working in the area of youth homelessness with its inherent problems is extremely stressful and that people can only work in the area for a certain time. Due to the buoyant economy and the huge financial rewards on offer in other less demanding areas, health boards and the voluntary agencies are experiencing increasing difficulties in filling positions. This has a knock-on effect on training and skill levels in the sector.

\section{Drug Abuse, Prostitution and Begging}

The Eastern Health Board Report of Working Party on Children in Prostitution which was published in September 1997, found that the vast majority of those surveyed had been or were currently out of home. There is no doubt that homeless young people due to their vulnerability and lack of resources are seriously at risk of becoming involved in drugs, prostitution and crime. These young persons will require additional services.

While not all children who beg are homeless, there is a strong connection between begging and homelessness. Children who beg may be exposed to influences such as drug abuse and child prostitution.

\section{Aftercare}

The Focus Ireland Report 'Left Out On Their Own' and the Report of the Forum on Youth Homelessness highlighted the link between being in care and youth homelessness. Whatever the reason a child is taken into care, when the term in care ends, every effort should be made in helping the young person re-integrate into their community. 
Section 45 of the Child Care Act, 1991 states that health boards may provide aftercare to young persons leaving care and also gives indications of what form the care might take. It is important that any aftercare plan should not be abruptly terminated on a person reaching the age of 18 .

\subsection{Summary}

This chapter defined youth homelessness and looked at the reasons why young people become homeless. Statistical information on youth homelessness including data from the Department of Health and Children's Child Care Interim Minimum Data Set for 2000 was outlined. The chapter recorded that the Department of Health and Children is addressing current information deficits by undertaking a major review of the information requirements of the child care services which includes youth homeless services.

Existing services supplied by health boards for homeless youth are outlined including the extensive changes introduced over the past year in the eastern region and a summary of the views of young people who were out of home and were consulted during the course of the preparation of the Forum Report and the consultation on The National Children's Strategy is reproduced. In addition, the gaps in existing services identified in the Forum Report are outlined. 


\section{CHAPTER 3}

\section{Objectives of the Strategy}

\subsection{Goal of the Strategy}

As outlined in Chapter 1, the goal of the strategy is:

"To reduce and if possible eliminate youth homelessness through preventative strategies and where a child becomes homeless to ensure that he/she benefits from a comprehensive range of services aimed at reintegrating him/her into his/her community as quickly as possible".

This goal reflects the strong preventive approach underlying the strategy which is aimed at reducing and eventually eliminating youth homelessness. This is an ambitious goal and it will obviously take time to achieve. The goal reflects this reality in recognising that services are needed to cater for young homeless people. Again the objective of the services is to prevent the child from being homeless by assisting him or her to reintegrate into his or her community.

\subsection{Guiding Principles}

The strategy is informed by the principles of the UN Convention on the Rights of the Child, which Ireland ratified in 1992. The Convention is in essence a 'bill of rights' for all children. It contains rights relating to every aspect of children's lives including the right to survival, development, protection, and participation.

The underlying principles of the Convention may be summarised as follows:

(i) Non-discrimination (Article 2): All rights apply to all children without exception. The State is obliged to protect children from any form of discrimination and to take positive action to promote their rights.

(ii) Best Interests of the Child (Article 3): All actions concerning the child shall take account of his or her best interests. The State shall provide the child with adequate care when parents, or others charged with that responsibility fail to do so.

(iii) Survival and Development (Article 6): Every child has the inherent right to life, and the State has an obligation to ensure the child's survival and development.

(iv) The Child's Opinion (Article 12): The child has the right to express his or her opinion freely and to have that opinion taken into account in any matter or procedure affecting the child.

The Convention recognises the critical role of the family in the life of a child. It states that the family, as the fundamental group of society and the natural environment for the well-being and growth of all its members and particularly children, should be afforded the necessary protection and assistance so that it can fully assume its responsibilities in the community.

The strategy also reflects the principles and spirit of the Child Care Act, 1991.

\subsection{Objectives}

There are twelve objectives which flow from the overall goal of the strategy. These reflect the comprehensive nature of the response required to deal with the needs of homeless children. They recognise the importance of supporting the family and the wider community in realising the overall goal. Young people who are homeless are not a homogeneous group, therefore, there is a need to ensure that services can match individual needs more appropriately. While the objectives are listed individually, it is important to note that they are very much interlinked. In implementing the strategy, it will be important to progress each of the objectives if the overall goal is to be progressed. 
The objectives have been divided into three categories:

\section{Preventive Measures}

1. Family support and other preventive services will be developed on a multi-agency basis for children at risk of becoming homeless. In particular, this will incorporate a generic* out of hours crisis intervention service and where necessary multi-disciplinary teams to target at risk young people.

2. Schools will actively support children at risk of homelessness e.g. truanting children and those who leave school early using the structures proposed under the Education Welfare Act, 2000.

3. Local communities will be supported to assist children at risk of becoming homeless and their families.

4. Aftercare services for children leaving foster care and residential care, and other services provided by a health board such as supported lodgings and for those leaving centres for young offenders, will be strengthened so that children are supported in making the transition to living independently or returning to their families.

\section{Responsive Services}

5. Emergency responses will be provided promptly to children who become homeless; these services will be accessible and acceptable to this client group. Specialised 24 Hour Reception Services will be provided in cities where appropriate.

6. A comprehensive assessment of children who become homeless will be carried out as the basis for individual action/care plans for case management/key working with the young person where necessary.

7. A range of accommodation arrangements will be provided for children who are unable to return home as part of an integrated response to the child's needs.

8. A range of supports will be provided to meet children's health, educational and recreational needs based on each child's action/care plan and aimed at reintegrating the child into his/her community as quickly as possible.

\section{Planning/Administrative Supports}

9. Health boards are responsible and will take the lead role in implementing the Youth Homelessness Strategy in their area; effective arrangements for co-ordination with both statutory and voluntary service providers will be put in place.

10. Each health board will facilitate ease of access to its youth homelessness services through the development of multi-access information points.

11. Effective information systems on homeless young people will be developed including a database accessible to both voluntary and statutory service providers.

12. Ongoing evaluation will be conducted at both local and national levels of the effectiveness of interventions to prevent homelessness occurring and of the services to assist and support young people who become homeless.

* That is a generally available out of hours crisis intervention service not one exclusive to the youth homeless emergency services. 


\subsection{Preventive Measures}

\section{Objective 1}

Family support and other preventive services will be developed on a multi-agency basis for children at risk of becoming homeless. In particular, this will incorporate a generic* out of hours crisis intervention service and where necessary multi-disciplinary teams to target at risk young people.

\section{Policy Context}

"Family support services" is the collective title given to a broad range of provisions developed by a combination of statutory and voluntary agencies to promote the welfare of children in their own homes and communities. These services are provided to particularly vulnerable children in disadvantaged areas and often include pre-school, parental education, development and support activities as well as home-maker and visiting schemes and youth education projects (M. Murphy Administration, Vol 44, No. 2, 1996 P. 76).

The Child Care Act, 1991, places a statutory requirement on health boards to promote the welfare of children who are not receiving adequate care and attention and to have regard to the principle that it is generally in the best interests of a child to be brought up in his or her own family. Section 3 of the Act specifically states that health boards should provide family support services.

The Government established the Springboard Initiative to develop family support services. This comprises projects in each health board area which involve statutory and voluntary agencies providing services at local level for vulnerable children (primarily aged 7 - 12) and their families. "A Guide to What Works in Family Support Services for Vulnerable Families" prepared as part of the evaluation of the Springboard Initiative, outlined the more prominent types of intervention available and reviewed the research literature into their effectiveness.

As well as health boards other state agencies such as the Departments of Social, Community and Family Affairs, and of Justice, Equality and Law Reform also have important roles in providing family support. This support should be provided in partnership with voluntary agencies and local communities. Family support and other preventive services can play a central role in supporting children at risk of becoming homeless and in supporting their families. Locally based neighbourhood youth projects working with at risk marginalised, young people and their families in their own local communities have been identified as one such intervention. This broad range of supports includes lone parent supports, parenting courses, marriage/family counselling, alcohol and drug treatment programmes, psychiatric assessment and treatment. There is a need for state agencies, voluntary organisations and communities to co-operate in providing a continuum of support from the time a child is born through to the age of eighteen which flexibly meets the needs of families. Current thinking suggests that to be most effective family support services should be integrated, community based and targeted at children and families who are most in need.

The Forum Report and the Crisis Intervention Services for Children Report identify the importance of tackling the problem of children at risk of homelessness in local areas through locally based services. The provision of a generic crisis intervention service and multi disciplinary teams i.e. where necessary in local areas to provide support to at risk children and their families are identified as important measures in this regard.

\section{Actions Required}

- Health boards, the Department of Social, Community and Family Affairs and other state agencies and their community partners will co-operate and work together to expand family support services and ensure that a comprehensive range of services are developed to cater for the diverse family support needs of children aged $0-18$.

- Family support services will target young people and families at risk to improve young peoples lives and prevent crises/breakdowns which may lead to the young person becoming homeless.

- Each health board will devise, in collaboration with the relevant statutory and voluntary agencies, as part of a two year plan to address youth homelessness, a strategy aimed at preventing youth homelessness as part of the development of a comprehensive provision of early intervention/prevention services to children at risk.

* That is a generally available out of hours crisis intervention service not one exclusive to the youth homeless emergency service. 
- This strategic plan will indicate the family support services that are currently in place and identify the services that will be developed to ensure that a comprehensive range of services to provide for the diverse family support needs of children aged 0-18 specifying the services for each age group (e.g. 0-5, 5-11 etc.). The plan will be integrated, community based and targeted at children and families who are most in need.

- The plan will aim to identify as early as possible the cohort of children at risk and potentially at risk of becoming homeless, the range of measures needed to prevent them becoming homeless, and the resource implications involved in each region. It will include provision for a locally based generic crisis intervention service and for the use of multi-disciplinary teams where necessary to target children at risk of homelessness and their families. 


\section{Objective 2}

\section{Schools will actively support children at risk of homelessness e.g. truanting children and those who leave school early using the structures proposed under the Education Welfare Act.}

\section{Policy Context}

The Department of Education and Science document "The New Deal: A Plan for Educational Opportunity (1999)" acknowledged that "not finishing school is the most significant indicator of those likely to be caught in cycles of disadvantage". Homelessness is one of the most visible forms of disadvantage. Indeed, there is a clear correlation between low educational attainment, poor school attendance and early school leaving and youth homelessness. In one study, $60 \%$ of the young homeless people surveyed had left school by the age of 14. The Forum Report noted "early school leaving and poor school attendance are indicators of risk of homelessness. Homelessness, in turn, affects education and training opportunities for young people. Shortcomings in education, therefore, figure as both indicators and effects of youth homelessness".

Schools, home based and community based tuition after school and alternative projects such as City Motor Sports, Carline and Youthreach can play an important role in identifying and providing active support, in conjunction with other statutory agencies, to children who are at risk of homelessness. Schools and alternative projects need to be actively supported in this regard. Measures such as the '8-15 Year Old Early School Leaver' and the 'Stay in School' initiatives have been piloted over the last couple of years to tackle early school leaving. The expansion of the National School Psychological Service and other measures to address special education needs are also important.

There is a clear need for a national framework within which issues relating to the educational welfare of children including the causes and effects of truancy and attendance problems can be addressed. The Education Welfare Act, 2000, provides this framework. The Act provides for the establishment of a National Educational Welfare Board (NEWB) whose function will be to ensure that each child attends a recognised school or otherwise receives an adequate level of education. The Board will also assist in the formulation of Government policies to promote school attendance. It will appoint educational welfare officers to work with schools in addressing non-attendance and in assisting students who are having problems attending school. The Minister for Education and Science as a first step has established a Board designate for an interim period to develop a strategic plan for implementing the various functions of the NEWB in advance of its being placed on a statutory footing. The framework provided by the Act will make an important contribution in tackling youth homelessness through preventive measures.

\section{Actions Required}

- Implementation of the Education Welfare Act, 2000, including the establishment of the National Education Welfare Board (which has the responsibility for implementing the Act and ensuring that its objectives are met). As a first step a Board designate has been established for an interim period to develop a strategic plan for implementing the various functions of the NEWB in advance of its being placed on a statutory footing.

- The National Education Welfare Board will specifically support schools in supporting children at risk of homelessness and be cognisant of the important role that education welfare officers and schools can play in early intervention/prevention and support to families to keep children in education. Special needs education is of particular relevance in this context.

- The National Education Welfare Board will devise a two year plan, with the strategic aim of identifying and targeting young people at risk of homelessness so as to support them in school or alternative projects such as Youthreach.

- The Board will work closely with health boards and other agencies in this area. Issues such as co-ordination on information exchange, confidentiality, the development and use of a tracking system of school students at risk of homelessness, linking the work of health board led multidisciplinary teams set up to target children at risk of homelessness with schools and education welfare officers and the need for research are some of the issues that will be considered in this context.

- Early school leaving will also be tackled by the full implementation of the Stay in School Initiative and the 815 Year Old Initiative. 
- Child Protection Committees are being set up at regional and community care level to plan and monitor the implementation of 'Children First: National Guidelines for the Protection and Welfare of Children'. These interagency committees under the chairmanship of the health boards may provide a forum for facilitating coordinated interagency action to prevent youth homelessness. 


\section{Objective 3}

\section{Local communities will be supported to assist children at risk of becoming homeless and their families.}

\section{Policy Context}

The National Children's Strategy recognises the importance of vibrant communities for the well being of children and families.

Outside their families the most immediate support for children comes from local communities. Despite the increased mobility of people, the growth of individualism and other stresses brought on by longer working hours and general activity, the social networks between children, families and their communities remain significant and strong linkages in the everyday lives of children" (The National Children's Strategy p. 76).

Strong community development supported by both the statutory and voluntary sectors has been a notable feature in this country. State support for community development includes the Integrated Services Process (which has been piloted in four areas and aims to tackle urban disadvantage and crime through enhanced family support services), the Springboard Initiative and the Family and Community Resource Centre Programme, which help to combat disadvantage by improving the functioning of the family unit. It also includes the 'Revitalising Areas by Planning, Investment and Development' (RAPID) initiative by the Government which targets the 25 most disadvantaged urban areas in the country for priority investment and development in housing, health, education, childcare and community facilities including sports facilities, youth development, employment. The RAPID Programme requires the appropriate state agencies to respond to the priorities identified in plans drawn up for each designated area. While the RAPID Programme does not have an administrative budget per se it is designed to frontload NDP expenditure through the appropriate state agency into the areas of greatest need. Strand II of the RAPID Programme which will focus on the provincial towns, is currently being developed by an Interdepartmental Team led by the Department of the Environment and Local Government. Provincial towns with a population in excess 4,000 (including environs) are included for assessment in the programme. The identification process is being managed by Area Development Management (ADM). Towns below this population threshold are being assessed by CLARE Programme for rural disadvantaged areas, which is the responsibility of the Minister of State for Rural Development. Fostering strong communities and community supports for the family, not just the child, have a vital role in tackling disadvantage including youth homelessness.

Co-ordination of the activities of state agencies, voluntary bodies and communities in providing family support and community development at local level will be enhanced. The National Children's Strategy identifies the important role in relation to improved co-ordination at local level created by the establishment of County and City Development Boards which will prepare local development strategies to guide community development in its broadest sense. Specifically the County and City Development Boards are charged with responsibility for drawing up a ten year integrated co-ordinated strategy for their local authority area drawing upon the actions and plans of all state agencies and local development organisations in their area. All County and City Development Boards have a Social Inclusion Measures Group whose focus is to address social inclusion issues. The Youth Homeless Forum in each health board area (see page 36) should link in with the relevant Social Inclusion Measures Group as appropriate. The Improved co-ordination will not only benefit children in general but can play a vital role in preventing youth homelessness.

\section{Actions Required}

- Health Boards in devising their two year plans to address youth homelessness will take account of the need to ensure that their plans facilitate improved co-ordination of community development including the local development strategies devised by County and City Development Boards.

- County and City Development Boards in devising local development strategies to guide community development in its broadest sense will have regard to each Health Board's two year plan to address youth homelessness and the important role that local community development can play in helping to prevent youth homelessness. The Youth Homelessness Forum in each health board area (see Objective 9 on page 36) should link in with the relevant Social Inclusion Measures Groups of the County and City Development Boards as appropriate.

- The National Children's Office will, in conjunction with relevant government departments and state agencies, ensure that policies on community development take account of the need to facilitate the prevention of youth homelessness. 


\title{
Objective 4
}

\begin{abstract}
Aftercare* services for children leaving foster care and residential care, and other services provided by a health board such as supported lodgings and for those leaving centres for young offenders, will be strengthened so that children are supported in making the transition to living independently or returning to their families.
\end{abstract}

\section{Policy Context}

There is clear evidence that young people formerly in the care of the state, in health board or other institutional care are particularly vulnerable to homelessness and other difficulties. "Left Out On Their Own", a study of young people leaving care in Ireland found that $32 \%$ of children leaving health board care after six months had experienced some form of homelessness ( $16 \%$ of the children concerned were actually homeless after six months). As well as this older group of young people younger children returning from a residential or foster care placement to the family home may also be vulnerable to homelessness.

While there are no unplanned releases from centres for young offenders the "Left Out On Their Own", study also identified young people leaving these institutions as being vulnerable to homelessness. The Finglas Centre for Young Offenders has developed the Grove Programme which has been in operation since mid-1999 and provides a pre-release/step-down facility which prepares young people for reintegration into family life and independent living. It also provides hostel accommodation for continued voluntary placement, continuing education and supported work placement. Such initiatives are important in preventing homelessness. Similiar pre-release and step-down facilities will be established at the Oberstown and Trinity House Young Offenders Centres.

In the Report of Findings Relating to Inspection of Children's Residential Centres (October 2000) the Social Services Inspectorate summarising the findings of its inspections of a number of health board run residential centres, in relation to aftercare, concluded that there is little "...evidence of a clear and costed programme in place for the support of young people leaving care. Generally, planning for young people leaving care is being left late and in some cases it is not happening at all. Too often young people are leaving care in an unplanned way, and this is not conducive to promoting their welfare". Some steps have been taken in both the health and education sectors on aftercare. Indeed the report of the Social Services Inspectorate cited examples of outreach support and independent living programmes of a high standard being provided for young people. These arrangements need to be formalised, provided in a planned way and provided to all children leaving the care of the state.

Preparation for leaving care, whether to return to the family home in the case of younger children or to make the successful transition to independent living for older children, is an integral part of the care process. It is an essential element in preventing homelessness among both groups. In the case of younger children returning to the family home, this may require a range of family support including social work assistance provided by the health board as well as assistance in relation to school. For older children, whether formally in care or availing of services provided by or on behalf of a health board such as supported lodgings, aftercare services such as transitional housing and support in education/training are required as well as specialist services.

Local authorities also have an important role to play in tackling this problem through the provision of accommodation such as 'scatter flats' which are designated units of accommodation for those who need support in existing housing complexes run by the authority. The Forum Report recommended the drawing up of national guidelines on aftercare. The recently published National Standards for Children's Residential Centres, devised by the Department of Health and Children and the Social Services Inspectorate in conjunction with representatives of the Health Boards, provides useful and constructive guidelines for promoting the quality of care including aftercare in children's residential centres. As part of the Government's overall strategy for tackling homelessness the Departments of Justice, Equality and Law Reform, Education \& Science, and Health and Children have drawn up preventative strategies aimed at preventing homelessness amongst high risk groups including children in residential care and in centres for young offenders which are set out in Homelessness-Preventative Strategy to be published by the Department of the Environment and Local Government.

\footnotetext{
* The term aftercare is generally used to refer to young people who have by agreement left the care of a Health Board/agency but are still in need of support of different types. This would include young people who leave care on reaching eighteen years of age.
} 


\section{Actions Required}

- Each health board, in collaboration with the local authorities and other relevant statutory and voluntary agencies, as part of its two year plan to address youth homelessness will devise a comprehensive strategy for effective aftercare having regard to the following Protocol. This will involve identifying the range of measures in relation to accommodation, education, training and other supports which are needed for effective aftercare and the resources required by the agencies involved. An underlying objective of this approach is to ensure that the young person does not become homeless as an adult.

- Aftercare Protocol:-

- Aftercare is an integral part of the care process, it is not an optional extra.

- Each health board must ensure that a written policy in relation to aftercare is prepared and communicated to all its staff including those working in residential centres. This statement outlines all aspects of support and entitlement for the young person concerned.

- Staff will be familiarised with this policy and will be supported to ensure that it is implemented.

- A specific budget will be set aside for aftercare support.

- A designated person will be appointed to provide aftercare support for each young person leaving care including those leaving foster care or availing of other services provided by or on behalf of a health board such as supported lodgings.

- In residential care the key worker appointed for each child has specific responsibility to support the transition of the young person leaving the centre.

- Every residential centre will appoint an aftercare support officer so that policy on aftercare is adhered to and to ensure that an aftercare support plan is in place for each young person leaving care.

- An aftercare support plan will be drawn up as part of the overall care plan for each young person. It must be drawn up well in advance of the young person leaving care and must set out a clear and costed aftercare support programme. The National Standards for Children's Residential Centres states in relation to preparation for leaving care that 'two years prior to a young person reaching the legal age of leaving care the care plan will outline the preparation and support in place for the young person. Included will be the named person who will maintain contact with the young person after they leave the centre, the financial support available to the young person, the living arrangements and support available in times of illness, crisis or seasonal celebration'.

- The aftercare support plan will cover the various issues which are necessary to effect a successful transition to independent living, return to their family or other appropriate arrangement such as:

role of keyworker/carers in aftercare including support in times of crisis etc

accommodation

education /training

employment

financial support and financial management, (the Department of Social Community and Family Affairs Management Advice and Budgeting Service- MABS- could provide a practical input in this regard)

peer group support

other supports e.g. counselling 
- The plan may need to be reviewed to take account of specific issues which arise.

- Support will continue until the young person has settled independently or in some other appropriate arrangement.

- The young person and his/her parents or carers as appropriate will be involved in developing the plan.

- Each health board will monitor and evaluate the outcomes of its aftercare provision and report on this in the context of its annual Section 8 Report ( Section 8 Child Care Act, 1991).

- The centres for young offenders which are under the aegis of the Department of Education and Science operate on a multi-disciplinary basis and no child or young person is released without:-

follow up from a key worker

interventions with schools or Youthreach or other centres if the young person wants to pursue further study

pre-release programmes with the young person's family

placement in a hostel if the young person cannot be accommodated at home

- To strengthen aftercare provision pre-release and step-down units will be established at the Oberstown and Trinity House Centres for Young Offenders as a matter of priority i.e. in line with the steps set out in Homelessness-Preventative Strategy to be published by the Department of the Environment and Local Government.

- The National Children's Office will initiate a cross sectoral examination of aftercare in conjunction with the Department of Health and Children, other Departments and relevant agencies in order to review progress. This review will be completed by the end of the two years covered by this strategy. 


\subsection{Responsive Services}

\section{Objective 5}

Emergency responses will be provided promptly to children who become homeless; these services will be accessible and acceptable to this client group. Specialised 24 Hour Reception Services will be provided in cities where appropriate.

\section{Policy Context}

Over the past number of years considerable financial resources and additional staffing have been directed at the youth homeless emergency services particularly in the Dublin area. The youth homeless emergency services in the Dublin area have been the subject of detailed analysis. The Forum Report and the Report of the Review Group on Crisis Intervention Services for Children ( December 2000) have considered the matter.

From this experience it is clear that if our goal is to reduce and if possible eliminate youth homelessness, not only must the youth homeless emergency services work effectively but they must be part of an effective continuum of services. The objective must be to identify and intervene with young people in a focused co-ordinated way and return them to their local area as soon as possible. This may require a 24 hour centrally based specialised multidisciplinary Reception Service in the larger urban areas, in addition to the locally based generic crisis intervention service and multidisciplinary teams referred to in Objective 1 . For a small number of hard to reach clients the latter will provide an integrated service to meet all the client's needs. This will be the exception rather than the rule. Clear protocols and strong links between the two services are needed to ensure that children who become homeless are returned as soon as possible to their families or local communities and that the supports that are needed are put in place. The Social Services Inspectorate has drawn attention to the fact that there is some evidence from its inspections to suggest that children 'in care' may at times be placed in the youth homeless emergency services. Emergency residential services should not be used in this way. Suitable alternative arrangements must always be made in such circumstances.

In addition based on the findings of the Forum Report and the Report of the Review Group on Crisis Intervention Services for Children it is considered that:

- emergency accommodation should be a point of entry only for those in a crisis from which the young person should be transferred to appropriate care. It should not form part of a routine pattern of response to young homeless people.

- provision of emergency accommodation should be made available for a sufficient period to allow a proper assessment of the needs of the young homeless person.

- emergency accommodation should be locally based.

Given the clear dangers posed by exposure to "the culture of homelessness", health boards must be prompt and proactive in their emergency responses. Some children and young people will seek to access the emergency service others may not. Outreach services will be needed to identify the children in need of help in the latter group.

\section{Actions Required}

- Each health board as part of its two year plan to address youth homelessness will assess its emergency response services for homeless children, having regard to the extent of youth homelessness and the needs of the children in its area and ensure that proactive and prompt emergency services appropriate to the needs identified are in place.

- The health boards, in developing the emergency services will have regard to the following principles:-

- Emergency accommodation will be a point of entry only for those in a crisis from which the young person will be transferred to appropriate care. It will not form part of a routine pattern of response to young homeless people. 
- The emergency service will be easily accessible and well advertised. The objective must be to identify and intervene with young people in a focused co-ordinated way and return them to their local area as soon as possible. This may require in addition to the locally based generic crisis intervention service and multi disciplinary teams referred to in Objective 1 a centrally based specialised multidisciplinary Reception Service in the larger urban areas.

- In addition, outreach services and street workers may need to be provided on a 24 hour a day seven day a week basis in urban areas to tackle the "hidden homeless" problem i.e. where young people do not come to the attention of the health board community care team or to other state services in the ordinary course. Account needs to be taken of the particular needs of young unattached travellers and unaccompanied minor asylum seekers in this context.

- An adequate number of locally based emergency placements will be available in a range of suitable residential, foster care and supported lodging arrangements. Younger children particularly those under 12 who are taken into care should be placed in foster care, where they cannot be returned home unless cogent reasons exist for other exceptional arrangements to be made.

- The use of hospital beds for social admissions has declined and should be phased out over the next twelve months.

- Provision of emergency accommodation will be made available for a sufficient period to allow a proper assessment of the needs of the young homeless person.

- Emergency residential services will not be used to cater for children discharged from residential care in advance of leaving care age. Suitable alternative arrangements must be made in such circumstances. 


\section{Objective 6}

\section{A comprehensive assessment of children who become homeless will be carried out as the basis for individual action/care plans for case management/key working with the young person where necessary.}

\section{Policy Context}

Once a homeless child has been placed in safe emergency accommodation there is then a requirement to assess the child's needs and to devise an individual action or care plan. This is consistent with one of the central principles identified by the Forum Report: that services should focus on the needs of young homeless people and respond accordingly. The Report of the Review Group on Crisis Intervention Services for Children identified the importance of providing an integrated service to meet the needs of the young person through the use of a case management/key worker approach. This would involve a designated member of a local area or central Reception Service team (as set out at Objective 5) having responsibility for active liaison contact with the young person and for co-ordination of the various services the young person may need.

The lead role in performing the comprehensive assessment and in drawing up the individual action/care plan should be undertaken by a designated key worker (who may but would not necessarily be a social worker although social work input will be necessary) as part of the local or Central Reception Service Team multi-disciplinary team which would comprise other staff in the health board and the wider health service, schools and the education/training sector. Where there is potential for a homeless child to return to the family home, every reasonable effort should be made to achieve this objective. It is clearly necessary to treat this as a priority and to target resources to optimise the chances of success.

For the assessment to be comprehensive all the needs of the child must be addressed. This can only be done in a child centred way through a multi-disciplinary and inter-agency co-ordinated response. The young person himself and depending on circumstances his parent(s) and/or members of his extended family would have an integral role in this process. The potential of the Family Welfare Conference model should be recognised in this context.

Children First - National Guidelines for the Protection and Welfare of Children provides guidance on the procedures to be followed where homeless children may have been abused. Given, that abuse within or outside the home may be an underlying reason for the young persons homelessness any concern about the care and protection of a homeless child should be dealt with in the same way as any other child protection concern. Consideration of appropriate legal action under the Child Care Act, or other relevant legislation, will form a central part of the assessment process.

This may give rise in certain circumstances to the health board pursuing an Emergency Care Order or it may lead to the voluntary reception of the child into the care of the board. If grounds for receiving the homeless child into care are not clear or do not exist and there appears to be no suitable accommodation for the child, then the health board has an obligation to provide him or her with a place to stay which is suitable for his or her needs. This placement should be short term, pending a comprehensive assessment.

When the assessment and plan have been completed the case management/key worker approach should be used to ensure an integrated focus on the young person and his or her needs. The core case planning and review structure led by the key worker and involving multi-disciplinary and multi-agency monitoring should be operated on a regular and flexible basis.

\section{Actions Required}

- A comprehensive assessment of the child's and his family's needs will be undertaken by the health board as soon as possible after the child has been placed in emergency care. In the case of younger children who for whatever reason cannot be returned home strong grounds will exist in relation to their age alone for them to be taken into care. The lead role in performing the comprehensive assessment and in drawing up the individual action/care plan will be undertaken by a designated key worker as part of the local or Central Reception Service multi-disciplinary team which would comprise other staff in the health board and the wider health service, schools and the education/training sector and an action/care plan drawn up for the child. Health Board management will ensure that designated key workers receive all the support necessary to carry out this role.

- The comprehensive assessment will be child centred and will require a multi-disciplinary and inter-agency coordinated response (including not only health board child care personnel but other staff in the wider health service and from the local authorities, education and the training sectors). The young person himself and depending on circumstances his parent(s) and/or members of his extended family would have an integral role 
in this process and in drawing up the care/action plan. The development of Family Welfare Conferences in this context will be considered as the aim if at all possible will be to assess and support the young person in the context of their own family. Family mediation may also be important in this context.

- Each health board will ensure that any child protection concern in relation to a homeless child will be speedily dealt with in accordance with the appropriate procedures.

The comprehensive assessment will include the following:

- Establish why the child left home;

- An assessment of the potential for the child to go back to his/her family home, including whether family support is needed to achieve this;

- An assessment of the child's physical, social and psychological well being including the need for medical treatment or treatment for drug, alcohol problems etc;

- An assessment of the short and longer term accommodation/care arrangements for the child if he/she is unable to return home;

- An assessment of the child's education and training needs and the social, cultural and sporting links necessary to allow the child to have similar opportunities to other young people;

- Each health board in devising its two year plan to address youth homelessness will identify, in collaboration with the local authority education and training sectors, the measures necessary to ensure that this objective is attained;

-When the assessment and plan have been completed the case management/key worker approach will be used to ensure an integrated focus on the young person and his needs. The core case planning and review structure led by the key worker and involving multi-disciplinary and multi-agency monitoring will be operated on a regular and flexible basis. A critical change in the young person's circumstances will warrant a review of the assessment and plan. 


\section{Objective 7}

A range of accommodation arrangements will be provided for children who are unable to return home as part of an integrated response to the child's needs.

\section{Policy Context}

As outlined in Chapter 2 health boards have developed a number of arrangements for accommodating homeless children in the medium to longer term (i.e. non emergency accommodation). These include foster care, supported lodgings, residential care (in hostels or other residential care arrangements), as well as semi-independent living arrangements and transitional housing.

The Forum Report recommended that interlinked groups of residential units, family placements and ancillary services (such as educational and training programmes) should be established. These arrangements should be flexible, localised and co-ordinated and should be developed to meet the multiple needs of young people. It also identified the need for specialised accommodation for particular groups of young people out of home e.g. drug abusers and young single parents. The tiered approach recommended by Social Information Systems referred to in the Report of the Review Group on Crisis Intervention Services for Children which details six tiers from harm reduction through assessment and stabilisation to re-settlement is a useful model to bear in mind in planning services.

In short, services for homeless children and young people must provide more than a roof over their heads, all aspects of a child's needs must be provided for. Moreover, there is a need for health boards not only to provide a suitable range of accommodation arrangements to cater for the needs of the homeless children in their area but to provide this accommodation as part of an overall plan and to link these services to specific educational, training and other day programmes. There is also a need to review and evaluate these services on a regular basis. The establishment of the Social Services Inspectorate and health board inspectorates is an important step in this context.

\section{Actions Required}

- Each health board as part of its two year plan to address youth homelessness will review its existing accommodation arrangements for homeless young people and having regard to the range of needs of the young homeless concerned will ensure that a suitable range of accommodation arrangements is put in place. These will include foster care, supported lodgings, residential care (in hostels or other residential care arrangements), as well as semi-independent living arrangements and transitional housing. These arrangements will be flexible and localised.

- The plan will facilitate co-ordination and linkages between accommodation arrangements and specific educational, training and other day programme services.

- The effectiveness of these measures will be subject to ongoing evaluation by the health boards and by the Social Services Inspectorate. A review of the overall national position will be undertaken after two years. 


\section{Objective 8}

\section{A range of supports will be provided to meet children's health, educational and recreational needs based on each child's action/care plan and aimed at reintegrating the child into his/her community as quickly as possible.}

\section{Policy Context}

Addressing the needs of homeless children is not simply confined to providing accommodation. The child's emotional, health, educational and recreational needs must also be met if she/he is to have the opportunity to develop the necessary skills for independent living in mainstream society. Drug abuse, alcohol abuse, prostitution, psychiatric and psychological difficulties have all been identified as problems associated with youth homelessness. While little research on the general health status of homeless young people has been conducted in Ireland, it is clear on the basis of studies of adult homelessness and studies conducted abroad that the physical and mental health of homeless young people in this country is worse than that of the general population.

Co-ordinating and delivering services with an integrated focus on the young person and his needs will be greatly facilitated by the case management/key worker approach referred to at Objective 6. One of the important roles of the key worker in this context is to ensure access to the range of services that the young person needs.

The services needed include medical and psychiatric assessments and care and the provision of specialised services to cater for drug and alcohol abuse and behavioural problems. While such services are in place or are being developed by health boards there is a need to provide tailored services for young homeless. There is also a need to collaborate with other agencies (e.g. local drugs task force on drug abuse) to ensure a comprehensive response to a young person's needs. The core case planning and review structure led by the key worker and involving multidisciplinary and multi-agency monitoring should be operated on a regular and flexible basis. Health Board Management and the management of the other agencies involved must ensure that the key worker is supported to ensure that this approach operates effectively.

Day programmes are another essential support service. Providing a daily routine that interests a child or young person who was homeless may pose a challenge. A variety of options need to be considered such as:

- Dedicated day services.

- Recreational, leisure, social, physical and sporting activities.

- Neighbourhood youth projects.

- Youthreach projects.

An integral element of successful day care is that it needs to be available on an ongoing basis. Young people should be asked for their views as a programme to be successful must be relevant and must provide what young people want (access to computers, music, TV, laundry, coffee shop). Education and training support services are important aspects of day programmes.

As part of the comprehensive assessment, an 'educational plan' should be drawn up for each child including any compensatory educational requirements for the child appropriate to their age and abilities. The plan should identify the resources and personnel required for its delivery. Tailored training programmes should be considered for older children. FÁS and other training agencies e.g. Comhairle will have a vital role to play in this regard. Links with other state agencies such the Department of Social Community and Family Affairs MABS service in relation to money management and budgeting should be made in developing these programmes.

The child's key worker will be responsible for overseeing the implementation of the action/care plan and ensuring that the child accesses the various services.

\section{Actions Required}

- Each health board in conjunction with its statutory and voluntary sector partners will ensure the provision of a range of support services i.e. day care, education and training, to address the needs of young homeless in its region as part of its two year plan to address youth homelessness. Steps will be taken to ensure speedy access to primary medical and dental services. Psychological, psychiatric and drug and alcohol treatment services, where necessary, will be made available as a priority to young homeless people.

- Consideration will be given to linking residential and other accommodation arrangements with specific training, education and day programme services. 
- A case management/key worker approach will be employed to ensure that services are delivered in a coordinated, integrated, client focused way to each young person. The core case planning and review structure led by the key worker and involving multi-disciplinary and multi-agency monitoring will be operated on a regular and flexible basis with a view to ensuring that the young person accesses and appropriately uses the range of services/supports necessary.

- The Irish Association of Young People in Care is developing an important advocacy role for those in care and for homeless young people. Children and young people will be facilitated in having access to forums for support and peer education to ensure that their voice is heard. 


\subsection{Planning/Administrative Supports}

\section{Objective 9}

\section{Health boards are responsible and will take the lead role in implementing the Youth Homelessness Strategy in their area; effective arrangements for co-ordination with both statutory and voluntary service providers will be put in place.}

\section{Policy Context}

The Forum Report identified the importance of youth homelessness services being provided in a co-ordinated way. The Report of the Review Group on Crisis Intervention Services for Children emphasised the importance of clarity of responsibility to ensure services are provided in the most effective way. At present, services for homeless children are provided by a range of voluntary service providers and directly by health boards which poses challenges in relation to both these principles.

Section 5 of the Child Care Act, 1991 places a legal obligation on health boards to provide suitable accommodation for children who have become homeless. This provision implicitly recognises that child homelessness is a child welfare issue and while it is recognised that one statutory or voluntary agency is not in a position to provide the comprehensive range of services needed there is a need for one agency to take the lead role at regional and local level and to co-ordinate its own services with the services provided by the other voluntary and statutory providers.

Health boards given their statutory responsibilities under the Child Care Act, 1991 in relation to youth homelessness and children who are not receiving adequate care or attention, should take the lead role in overseeing and ensuring the implementation of the strategy in their area. Specific arrangements in regard to the management of youth homelessness have been made by the Eastern Regional Health Authority as outlined in Chapter Two. Staff training and development programmes are considered essential to the successful implementation of the Strategy not only in the context of fostering effective multidisciplinary working but in relation to effective inter agency working also.

Local authorities, the education and training sectors, as well as voluntary providers will all need to collaborate closely with the health boards in implementing the strategy.

\section{Actions Required}

- Each health board, as part of its two year plan to address youth homelessness, will put in place arrangements to collaborate with the range of statutory and voluntary service providers to ensure that the plan provides for a comprehensive range of services to be delivered in a co-ordinated way. The plans will take account of the need for clarity of responsibility to ensure that services are provided in the most co-ordinated and effective way. The plans will provide for staff training and development and have particular regard to the need for effective multi-disciplinary and inter-agency working to be developed.

- A Youth Homeless Services Forum will be established in each health board area with representation from the local authorities, the education and training sectors, the Gardaí as well as voluntary providers. Representatives of the young homeless should be included in the Forum's membership. The Forum will be chaired by the health board concerned, as boards have statutory responsibility for youth homeless services. It will advise on the co-ordinated planning and monitoring of services for young people at risk of homelessness and those who are out of home. Child Protection Committees have been established at regional and community care level to plan and monitor the implementation of Children First: National Guidelines for the Protection And Welfare Of Children. Given that these committees represent the voluntary sector, Gardaí, schools, youth services etc i.e. the broad range of state bodies/agencies which should be involved, under the chairmanship of the health boards they may provide a suitable forum with changes in membership as necessary for this purpose. The Eastern Region already has a provider forum which will perform this function in that region. The Youth Homelessness Forum will link in with the Adult Homeless Fora in their region, as appropriate. 


\section{Objective 10}

Each health board will facilitate ease of access to its youth homelessness services through the development of multiaccess information points.

\section{Policy Context}

Youth homelessness services to be effective must be relatively easily accessible. The Forum Report recommended that a comprehensive directory of services should be compiled to enable young people who are at risk of homelessness or who are homeless to access services. The Report of the Review Group on Crisis Intervention Services for Children identified the need for multi-access and information points which are available to young people, parents, gardai, hospitals and other professionals.

The aim should be to ensure effective wide dissemination of services . A directory or guide is an important way of detailing the whole range of prevention/early intervention services and of youth homelessness services available and of providing the information necessary to access them. This should be complemented by a range of access points including 24 hour phone access, information in community centres posters and brochures in local areas and in the centres of cities as well as entry in service directories and the telephone directory. These initiatives should also be used to educate and inform the public about the extent and nature of youth homelessness.

\section{Actions Required}

- Each health board will compile a directory of youth homelessness services in collaboration with other state and voluntary agencies.

- Health boards will develop multi-access information points e.g. use of 24 hour phone access advertising, freephone services and of the internet in facilitating ease of access to services and in making the services more widely known. 


\section{Objective 11}

Effective information systems on homeless young people will be developed including a database accessible to both voluntary and statutory service providers.

\section{Policy Context}

The Forum Report identified the deficit in statistical information on youth homelessness as a major obstacle to measuring the extent of the problem and to planning the services required.

The importance of information and effective information systems in organising, planning and ensuring the effective delivery of child welfare services is recognised. The Department of Health and Children and the health boards have established a project team to devise proposals for the establishment of a national standardised integrated child care information system. It will consider the information deficits and other issues regarding youth homelessness and the introduction of a database.

Pending the development of such a system, the Department of Health and Children has introduced an Interim Minimum Data Set based on data compiled by each health board The statistical information on youth homelessness in Chapter 2 came from that data set.

It should be noted that a Crisis Intervention Service Database has been developed for the youth homelessness service in the eastern region and has the potential to be used as a tracking, monitoring and planning tool.

\section{Actions Required}

- The project team set up by the Department of Health and Children and the health boards to devise proposals for the establishment of a national standardised integrated child care information system will develop a national youth homelessness database accessible to both voluntary and statutory service providers as soon as possible.

- Protocols on exchange of information will be agreed between the relevant statutory and voluntary bodies concerned in each health board region.

- The Interim Minimum Data Set will be used pending the development of the national standarised integrated child care information system. 


\section{Objective 12}

Ongoing evaluation will be conducted at both local and national levels of the effectiveness of interventions to prevent homelessness occurring and of the services to assist and support young people who become homeless.

\section{Policy Context}

One of the national goals of The National Children's Strategy is that "Children's lives will be better understood; their lives will benefit from evaluation, research and information on their needs, rights and the effectiveness of services."

The National Children's Strategy identifies the limited empirical data and research-based understanding of children's lives in this country as a barrier to providing a more coherent approach. The absence of a fuller knowledge and understanding is reflected in children's relative invisibility within public policy debate. A number of initiatives are being taken to improve independent research to achieve the objectives set out in The National Children's Strategy including a children's research programme and a National Children's Research Dissemination Unit. Given the relative absence of research on youth homelessness this area will be prioritised.

Ongoing evaluation is an essential part of effective service provision at both a strategic and at a service delivery level. Planning, setting strategic parameters and service delivery will be dynamic processes which respond to changing circumstances and ensure that services are not only effective but are being delivered to meet the needs of the clients.

Ongoing evaluation will be an in-built part of the health board two year plans to address youth homelessness. At national level, a mechanism needs to be established to allow for a review of the effectiveness of regional responses under the new structures being established under the National Children's Strategy.

\section{Actions Required}

- Each health board/authority will provide for ongoing evaluation of the effectiveness of the youth homelessness services, including its prevention services, as part of its two year plan to address youth homelessness. This should include a Value for Money analysis. The Department of Health and Children will review the plans of each health board/authority annually and liaise with the National Children's Office in this regard.

- Each health board/authority will prepare an annual report on its youth homelessness services which will be submitted to the Department of Health and Children and the National Children's Office. Information on services etc contained in the annual report should be provided on a community care area basis.

- The Youth Homelessness Strategy will be monitored on an ongoing basis by the National Children's Office and reviewed annually and a report made to the Cabinet Committee on Children by the Minister for Children.

- Priority will be given to research on identifying the most effective services for supporting and assisting young people who become homeless (including special need groups and travellers) and on preventing youth homelessness in the context of the development of the children's research programme and the National Children's Research Dissemination Office. 


\section{CHAPTER 4}

\section{Implementation of the Strategy}

\subsection{Cross-Sectoral Approach}

Putting the Youth Homelessness Strategy into effect will require the commitment not just of health boards, which have statutory responsibility for youth homelessness but the support of other public agencies, including education and local authorities, the voluntary sector and local communities.

At national level, given the cross-sectoral dimensions of youth homelessness, the National Children's Office will have lead responsibility for driving and co-ordinating the actions necessary to ensure the successful implementation of the Youth Homelessness Strategy.

\subsection{Health Board Two Year Strategic Plan to Address Youth Homelessness}

Each health board will prepare a two year strategic plan to address youth homelessness following consultation with their statutory and voluntary partners in line with the preventive, service and administrative objectives set out in this Strategy. In the case of the three area health boards in the Eastern Regional Health Authority area a regional strategy will be drawn up.

The two year strategic plan will clearly identify, having regard to the extent of youth homelessness and children at risk of youth homelessness in each health board, the resource requirements (including detailed costings which identify the incremental staffing and other resources required), the steps that will be taken to put the actions required under each objective into effect and the targeted outputs. The plans will specify the health board/ authority's current expenditure on youth homelessness.

The two year strategic plan of each health board will be devised within three months of the publication of this strategy and a report made to the Minister for Children for consideration by the Cabinet Committee on Children. The plan of each health board will then formally be approved by the Minister. The implementation of the plans by health boards will be monitored and reviewed annually by the Department of Health and Children which will liaise with the National Children's Office to enable the Minister for Children to report on all aspects of the implementation of the Strategy to the Cabinet Committee on Children. The annual progress reports by the health board/authority on the implementation of its plan will show annual service activity, its cost and the outcomes achieved.

\subsection{Implementation of Other Objectives}

Where the implementation of the objectives of the strategy requires action by other state agencies (e.g. the National Education Welfare Board and the County and City Development Boards) a strategic plan will be devised within three months outlining the resources needed and the steps that will be taken to put the actions required under each objective into effect. These strategic plans will also be submitted through the relevant Department to the National Children's Office so that the Minister for Children can report to the Cabinet Committee on Children. Strategic plans of such agencies will also be reviewed on an annual basis by the relevant Department in conjunction with the National Children's Office.

The National Children's Office will provide support to health boards, government departments and other agencies in tackling problems (particularly cross-sectoral problems) which may arise in the implementation of the Youth Homelessness Strategy.

The National Children's Office will report to the Minister for Children on the implementation of the Strategy for discussion by the Cabinet Sub Committee on Children every six months. 


\subsection{Cost Implications}

Since mid 1997 over $£ 90$ million (€114.276 million) additional revenue funding has been invested through the health boards in the development of the child welfare services. Approximately $£ 9$ million ( $€ 11.428$ million) has been targeted at youth homelessness. $£ 7.6$ million (€9.650 million) of this has been targeted at the youth homelessness problem in the Eastern Region. Firm estimates of the cost of implementing the Youth Homelessness Strategy will not be available until each health board and the Eastern Regional Health Authority have drawn up their two year strategic plans. A range of service developments are involved including:

- the establishment of generic out of hours services;

- the setting up of multidisciplinary early intervention teams;

- the expansion of aftercare services;

- the provision of specialist services;

- the provision of accommodation including some expansion of emergency services.

It is apparent that financial resources will be required for the development of the wider child welfare services (e.g. early intervention services, aftercare etc.) in addition to specific youth homelessness services.

It is considered that the implementation of this strategy will not give rise to major additional costs for other Government Departments and Agencies. However its success will depend on developments under a number of complementary initiatives such as the RAPID initiative, the National Anti-Poverty Strategy, the Education Welfare Act 2000, "Homelessness - An Integrated Strategy" 2000 and the Homelessness-Preventative Strategy to be published by the Department of the Environment and Local Government. 


\section{APPENDIX 1}

Objective H National Children's Strategy Extract from National Children's Office, (2000)

Report of the Public Consultation on the National Children's Strategy.

Children will have access to Accommodation Appropriate to their needs.

\section{Policy Context}

All children must have access to good-quality housing appropriate to their needs. Although not homeless, some children are members of families living in inappropriate accommodation. The availability of public housing and the cost of private housing remain major issues for public policy. Measures are being taken arising from the National Development Plan, in particular the Local Authority Housing Programme and the Voluntary Housing Programme, and the Bacon Reports to address these problems.

Youth homelessness is a relatively new phenomenon which is predominately urban and is strongly associated with children leaving care. A 1998 study by Focus Ireland showed 32\% of children leaving Health Board care as having experienced some form of homelessness within the first six months. There are two categories of homeless children, those who are members of homeless families and those who have homes but who have decided to leave their homes for various reasons. The problem of children in homeless families is a separate problem and separate measures are in train under the aegis of the Department of Environment and Local Government in this regard.

Although there is a need for more research into the causes, nature and extent of child homelessness in Ireland, an approach to tackling it is now emerging. In common with poverty, homelessness, which is also alluded to in Article 27 of the UN Convention, is a significant barrier to participation and progress along the dimensions of children's needs, as it is associated with low educational take-up, high levels of unemployment and high levels of social deprivation. The increasingly complex structure of family life, the weaker structure of community supports available to families in urban areas, and issues such as drug abuse and alcoholism among parents contribute to the incidence of homelessness and combine to make the task of tackling it all the more difficult.

\section{Recent Initiatives}

- Publication of the Report of the Forum on Youth Homelessness in April, 2000.

- Launch of the Eastern Regional Health Authority action plan Youth Homelessness, and approval of funding in 2000 to implement the first phase of the plan.

Tackling the problems which lead to homelessness will require the co-ordinated efforts of the key agencies if the problem is to be overcome. The longer children remain homeless, the more difficult the task of re-integrating them into their families becomes, as they develop other problems such as involvement in drug taking and prostitution. Prevention and early intervention measures need to be taken to assist families and to provide supports within the community, directed towards keeping children with their families, or where that is not possible, providing assistance as soon as they decide to leave home. The measures outlined below are directed towards that end.

\section{Further Actions Proposed}

- To continue to ensure that families with children are prioritised for accommodation under the new streams of housing to become available under the Local Authority and Voluntary Housing Programmes.

- A National Strategy for Homeless Youth will be published by the end of the year 2000.

- Formal programmes to prepare young people for leaving care and to deliver after- care support will be introduced with the key objective of ensuring that no child leaving care is discharged into homelessness.

- The Housing Forum will review the impact on children of housing developments

- Young homeless people will be provided with an adequate emergency response, including a day service, education and training and drug treatment services where necessary, tailored to their special needs.

- Preventative and restorative programmes will be developed, both family and community based, and alternative supports to break the cycle of homelessness and reduce its incidence will be put in place. 


\section{APPENDIX 2}

\section{Documents and Publications consulted in the preparation of the Strategy}

Avramov, D.(Ed) (1998) Youth Homelessness in the European Union. Feantsa.

Child Care Act, (1991) Dublin: The Stationery Office.

Children Act, (2001) Dublin: The Stationery Office.

Collins, B. McKeown, K. (1992) Referral and Settlement in the Simon Community, Dublin: Simon Community of Ireland.

Department of Education and Science, (1999) The New Deal: A Plan for Educational Opportunity, Dublin: The Stationery Office.

Department of Education and Science, (1998) National Anti-Poverty Strategy Report, Dublin: Government Publications Office.

Department of the Environment and Local Government, (2000) Homelessness - An Integrated Strategy, Dublin: Department of the Environment and Local Government.

Department of Health and Children, (1999) Children First - National Guidelines For The Protection And Welfare Of Children, Dublin: The Stationery Office.

Department of Health and Children, (2000) National Interim Minimum Dataset, Dublin: Department of Health and Children.

Department of Health and Children, (2001) National Standards for Children's Residential Centres, Dublin: The Stationery Office.

Department of Health and Children, (2001) Report of the Working Group on Foster Care, Foster Care - A Child Centred Partnership, Dublin: The Stationery Office.

Department of Health, (1994) Shaping a Healthier Future - A Strategy for Effective Healthcare in the 1990s. Dublin: Government Publications Office.

Eastern Health Board, (1997) Report of the Working Party on Children in Prostitution, Dublin: Eastern Health Board.

Education Welfare Act, (2000) Dublin: The Stationery Office.

Focus Ireland, (1995) Here, There and Nowhere, a Study of Youth Homelessness in Tallaght, Dublin: Focus Ireland.

Forum on Youth Homelessness, (2000) Report of the Forum on Youth Homelessness, Dublin: Northern Area Health Board.

Homeless Agency, (2001) Shaping the future - an action plan on homelessness in Dublin 2001 - 2003, Dublin: Homeless Agency.

Kelleher, P. Kelleher, C. and Corbet, M. (2000) Left Out On Their Own -Young people leaving care in Ireland, Dublin: Focus ireland and Oak Tree Press.

Kelly, M. B. (1999) Out of House and Home, Dublin: Focus Ireland.

Lynott, M. Prendergast, C. Dudley, D. (2000) Report of the Review Group on Crisis Intervention Services for Children, Dublin: Northern Area Health Board (unpublished).

McKeown, K. (2000) A Guide to What Works in Family Support Services for Vulnerable Families, Department of Health and Children, Dublin: The Stationery office. 
Murphy, M. (1996) From Prevention to 'Family Support' and Beyond: Promoting the Welfare of Irish Children, Administration, Vol 44, (2), p76.

National Children's Office, (2000) Report of the public consultation on the National Children's Strategy (Based on a report compiled by Colgan \& Associates), Dublin: National Children's Office.

O'Connor, M. Williams, J. (1999) Counted In -Report of the Assessment of Homelessness in Dublin, Kildare, and Wicklow, Dublin: ESRI/Homeless Initiative.

O'Sullivan, M. Mid-Western Health Board, (1998) Prostitution in the Mid West Region, Mid-Western Health Board.

Perris, A. (1999) Youth Homelessness in Clondalkin, a community perspective, Clondalkin Area Partnership.

Social Information Systems Ltd (SIS), (2000) Review Report on Crisis Intervention Service (CIS) for Review Group on Crisis Intervention Services for Children, Northern Area Health Board (unpublished).

Social Services Inspectorate, (2000) Report of Findings Relating to Inspection of Children's Residential Centres, Dublin: Social Services Inspectorate.

The National Children's Strategy (2000), Our Children - Their Lives, Dublin: The Stationery Office.

UN Convention on the Rights of the Child, (1989) Offices of the United Nations High Commissioner for Human Rights, Geneva, Switzerland. 
NOTES 


\section{NOTES}




\title{
Department of Health and Children
}

An Roinn Sláinte agus Leanaí

\author{
Hawkins House Dublin 2
}

Teach Haicín Átha Cliath 2

Telephone (01) 6354000 VPN112

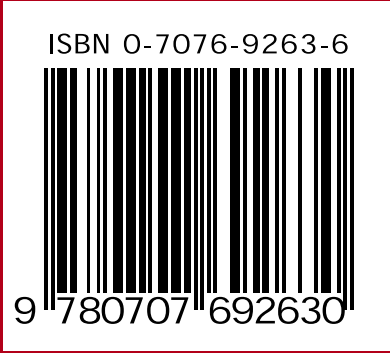

